\title{
ОПТИМИЗАЦИЯ ВОДНОГО РЕЖИМА ЧЕРНОЗЕМА ОБЫКНОВЕННОГО ЛЕСОСТЕПНОЙ ЗОНЫ КРАСНОЯРСКОГО КРАЯ
}

\section{V.V. Semenova, S.E. Badmaeva}

\section{THE OPTIMIZATION OF THE WATER REGIME OF CHERNOZEM OF ORDINARY FOREST-STEPPE ZONE OF KRASNOYARSK REGION}

Семенова Виктория Викторовна - ассист. каф. кадастра застроенных территорий и планировки населенных мест Красноярского государственного аграрного университета, г. Красноярск. E-mail: semviktori@mail.ru

Бадмаева Софья Эрдыниевна - д-р биол. наук, доц., зав. каф. кадастра застроенных территорий и планировки населенных мест Красноярского государственного аграрного университета, г. Красноярск. E-mail: s.bad55@mail.ru

Цель исследования - оптимизация водного режима чернозема обыкновенного среднесуглинистого при выращивании многолетних травосмесей на год расчетной обеспеченности осадками. Исследование проводилось на территории стационара "Новоселово», расположенного в лесостепной зоне в провинции разновидностей обыкновенных черноземов среднесуглинистых Чульмо-Енисейского южного округа, образованного на лессовидных суглинках четвертичных отложений. Для изучения режима орошения чернозема обыкновенного были заложены вегетационно-полевые опыты согласно схеме. Схема опыта по изучению водного режима чернозема обыкновенного: 1) контроль (без орошения); 2) предполивной порог увлажнения 80 \% НВ. Повторность опыта четырехкратная. Образцы отбирались буром Качинского через 10 см до глубины 50 см, влажность определялась термостатно-весовым методом подекадно, также до и после полива. Влагообеспеченность вегетационного периода в год проведения исследований характеризовалась как недостаточно увлажненная. Наблюдения за динамикой влажности почвы показали, что атмосфрерные осадки не обеспечивают оптимальную влажность растений, особенно в начале отраста-
Semenova Victoriya Victorovna - Asst., Chair of Inventory of Built-up Territories and Layout of Populated Areas, Krasnoyarsk State Agrarian University, Krasnoyarsk. E-mail: semviktori@mail.ru

Badmaeva Sofya Erdynievna - Dr. Biol. Sci., Prof., Head, Chair of Inventory of Built-up Territories and Layout of Populated Areas, Krasnoyarsk State Agrarian University, Krasnoyarsk.

E-mail: s.bad55@mail.ru

ния трав. Для поддержания влажности на уровне 80-100 \% НВ в мае было проведено два полива нормой по $300 \mathrm{~m}^{3}$ / га на варианте с орошением. Коэфффициенты водопотребления на орошении почти в два раза выше, чем на бozape.

Ключевые слова: орошаемые черноземы, наименьшая влагоемкость, режим орошения, осадки, поливы, динамика влажности, суммарное водопотребление, коэфрфициент водопотребления.

The aim of the study is to optimize the water regime of ordinary medium-loam Chernozem when growing perennial grass mixtures for the year of the calculated provision of precipitation. The study was conducted on the territory of the hospital "Novoselovo", located in the forest-steppe zone in the province of varieties of ordinary chernozems of medium-loamy Chulym-Yenisei southern district, formed on loess-like loams of quaternary deposits. To study the irrigation regime of ordinary Chernozem, vegetation and field experiments were laid, according to the scheme. The scheme of experiment in studying the water regime of ordinary chernozem: 1) control (without irrigation); 2) prewatering threshold moisture $80 \% \mathrm{HB}$. The repetition of the experience was fourfold. The samples 
were taken by Kachinsky drill after $10 \mathrm{~cm}$ to a depth of $50 \mathrm{~cm}$; the humidity was determined by thermostatic-weight method a decade, also before and after watering. The moisture content of growing season in the year of the research was characterized as insufficiently humidified. The observations of soil moisture dynamics showed that precipitation had not provided optimal plant moisture, especially at the beginning of grass regrowth. To maintain humidity at the level of 80-100 \% HB, in May, two watering norms $\sim 300 \mathrm{~m}^{3}$ / hectare on the variant with irrigation were carried out. Water consumption rates for irrigation were almost twice as high as for bogar.

Keywords: irrigated chernozems, lowest moisture capacity, irrigation regime, rainfall, irrigation, moisture dynamics, total water consumption, water consumption coefficient.

Введение. При создавшихся социальноэкономических условиях в Сибири в конце 90-х гг., большие площади орошаемых земель выведены из сельскохозяйственного оборота, оросительные системы во многих регионах не функционируют и по настоящее время. Вместе с тем в орошаемое земледелие были вовлечены наиболее плодородные черноземные почвы лесостепной и степной зоны. На многих оросительных системах полив производился с нарушением научно обоснованных режимов орошения, что привело к нарушению экологического равновесия в цепочке «вода - почва растение», поднятию уровня грунтовых вод на пониженных элементах рельефа, возникновению вторичного засоления, осолонцевания $[4,5,9,10]$. По настоящий день оросительные системы выведены из строя, орошаемые площади переведены в залежь или используются в богарном земледелии, и на значительной части орошаемых земель наблюдается неудовлетворительное состояние почвы [1, 3]. В условиях Сибири наиболее плодородные почвы (черноземы) формируются в естественных условиях при скомпенсированном гидротермическом режиме. В исследовании использовано соотношение $R / Q_{c}=0,8-1,1$, где $R$ - насыщенный радиационный баланс деятельной поверхности, ккал/см²/год; $Q_{c}$ - количество тепла, необходимого для испарения осадков, ккал/см²/год. Предполагая, что такое соотношение водных и тепловых ресурсов является оптимальным с точки зрения почвенных процессов и, исходя из особенностей водно-физических и химических свойств черноземных почв, поливы должны восполнять дефицит осадков в расчете на год оптимального естественного увлажнения, т. е. когда отношение $N\left(Q_{c}+M\right)$ не превышает $\sim$,81,1 (М - оросительная норма), а промывной режим не превышает $\sim 0,1$ суммарного испарения.

На сибирских черноземах независимо от водно-физических особенностей и вида возделываемых культур мощность слоя оптимального (до НВ) увлажнения вегетационными поливами должна быть ограниченной и не превышать 40 см. Причем предполивной порог влажности должен быть дифференцирован в зависимости от гранулометрического состава. При орошении легкосуглинистых черноземов вегетационные поливы необходимо проводить при снижении влажности корнеобитаемого слоя до $70 \% \mathrm{HB}$, тогда как на средне- и тяжелосуглинистых - до $80 \%$ НВ. В этом случае поливные нормы должны составлять 350-400 м³/га. При поддержании такого режима орошения создаются условия активного влагооборота в верхнем наиболее плодородном слое почвы, что способствует накоплению максимального сухого вещества на единицу общей массы урожайности и практически исключает потери поливной воды за пределы корнеобитаемого слоя почвы [2, 6-8].

Цель исследования: оптимизация водного режима чернозема обыкновенного среднесуглинистого при выращивании многолетних травосмесей на год расчетной обеспеченности осадками.

Методы исследования. Исследование проводилось на территории стационара «Новоселово», расположенного в лесостепной зоне в провинции разновидностей обыкновенных черноземов среднесуглинистых Чулымо-Енисейского южного округа, образованного на лессовидных суглинках четвертичных отложений. Для изучения режима орошения чернозема обыкновенного были заложены вегетационно-полевые опыты согласно схеме.

Схема опыта по изучению водного режима черноземаобыкновенного:

- контроль (без орошения);

- предполивной порог увлажнения 80 \% HB.

Повторность опыта четырехкратная. Образцы отбирались буром Качинского через 10 см до глубины 50 см, влажность определялась термо- 
статно-весовым методом подекадно, также до и после полива.

Результаты исследования и их обсуждение. Сумма среднесуточных температур за период активной вегетации сельскохозяйственных культур в этой зоне составляет $1400-1700{ }^{\circ} \mathrm{C}$. Основные показатели агроклиматических ресурсов земледельческой зоны лесостепи представлены в таблице 1.

Агроклиматические ресурсы земледельческой зоны

\begin{tabular}{|l|c|}
\hline \multicolumn{1}{|c|}{ Показатель } & Лесостепная зона \\
\hline Сумма среднесуточных температур за период активной вегетации & $1400-1700$ \\
\hline Основной период вегетации & \\
Tсут ${ }^{\circ}{ }^{\circ} \mathrm{C}:$ начало & $20.05-25.05$ \\
конец & $06.09-11.09$ \\
\hline Беззаморозковый период: & \\
начало & $22.05-1.09$ \\
конец & $01.09-18.09$ \\
\hline Осадки годовые, мм & $300-500$ \\
\hline Коэфффициент атмосферного увлажнения & $0,66-1,1$ \\
\hline Вероятность сухих и засушливых лет , \% & $12-52$ \\
\hline Среднесуточная температура наиболее теплого месяца, ${ }^{\circ} \mathrm{C}$ & $17,2-18,9$ \\
\hline Температура наиболее холодного месяца, ${ }^{\circ} \mathrm{C}$ & $(-18,0)-(-25,0)$ \\
\hline
\end{tabular}

Начало вегетационного периода варьирует с 20 по 25 мая. Окончание периода - 6-11 сентября. Среднегодовое количество осадков составляет 300-500 мм.
Водно-физические и агрохимические свойства чернозема обыкновенного до закладки опытов представлены в таблице 2.

Таблица 2

\section{Свойства черноземов обыкновенных опытного участка}

\begin{tabular}{|c|c|c|c|c|c|c|c|c|c|}
\hline \multirow{2}{*}{$\begin{array}{c}\text { Слой} \\
\text { см }\end{array}$} & $\begin{array}{c}\text { Плотность, } \\
\text { г/см }\end{array}$ & \multicolumn{4}{|c|}{$\begin{array}{c}\text { Водно-физические } \\
\text { свойства, мм }\end{array}$} & $\begin{array}{c}\text { Гумус, } \\
\%\end{array}$ & \multicolumn{3}{|c|}{$\begin{array}{c}\text { Агрохимические свойства, } \\
\text { мг/100 г }\end{array}$} \\
\cline { 3 - 10 } & & $\mathrm{HB}$ & МГ & В3 & ДАВ & & $\mathrm{NO}_{3}-$ & $\mathrm{P}_{2} \mathrm{O}_{5}$ & $\mathrm{~K}_{2} \mathrm{O}$ \\
\hline $0-10$ & 1,12 & 31,1 & 10,0 & 15,0 & 16,5 & 5,01 & 4,1 & 18,1 & 22,5 \\
\hline $10-20$ & 1,15 & 31,1 & 10,3 & 16,0 & 15,5 & 4,18 & 4,7 & 16,2 & 15,8 \\
\hline $20-30$ & 1,19 & 31,5 & 10,7 & 17,0 & 15,0 & 3,24 & 3,0 & 9,1 & 9,9 \\
\hline $30-40$ & 1,22 & 31,0 & 12,2 & 18,3 & 12,7 & - & 2,4 & 9,2 & 9,4 \\
\hline $40-50$ & 1,27 & 31,6 & 13,4 & 20,1 & 11,5 & - & 2,1 & 9,4 & 9,2 \\
\hline
\end{tabular}

Наименьшая влагоемкость по слоям колеблется в пределах 31,0-31,6 мм, диапазон активной влаги в изучаемом слое почвы варьирует от 16,5 до 11,5 мм.
В таблице 3 представлена влагообеспеченность вегетационного периода в год проведения исследования. 
Таблица 3

Влагообеспеченность вегетационного периода

\begin{tabular}{|l|c|c|c|c|c|c|l|}
\hline \multirow{2}{*}{ Показатель } & \multicolumn{6}{|c|}{ Месяцы исследования } & \multirow{2}{*}{ Увлажненность } \\
\cline { 2 - 7 } & 05 & 06 & 07 & 08 & 09 & $\begin{array}{c}\text { май- } \\
\text { сентябрь }\end{array}$ & \\
\hline Норма & $0,10-0,12$ & $0,25-0,27$ & $0,35-0,37$ & $0,40-0,42$ & $0,44-0,47$ & $0,31-0,33$ & Недостаточная \\
\hline Факт & $0,31-0,33$ & $0,49-0,51$ & $0,30-0,32$ & $0,60-0,62$ & $0,33-0,35$ & $0,41-0,43$ & Недостаточная \\
\hline
\end{tabular}

По влагообеспеченности вегетационного периода год проведения исследования был близок к среднемноголетним показателям, и увлажненность характеризовалась как недостаточно увлажненная.

Среднесуточные температуры воздуха и выпавшие осадки за вегетационный период растений были близки к среднегодовым показателям. Запасы влаги в начале отрастания трав первого укоса оказались ниже оптимальных значений: в контрольном варианте $\sim 1041 \mathrm{~m}^{3} /$ га, что соответствует $66 \% \mathrm{HB}$; на орошаемом варианте 1103 м $3 /$ га - $70 \%$ НВ. На варианте с орошением 2 мая был произведен полив нормой 300 м/га, что позволил поддерживать влажность почвы на уровне $82 \%$ HB.

Первая декада мая характеризовалась засушливостью, осадков не выпало. На контрольном варианте отмечалось снижение влажности до $\sim 64 \%$ НВ и запасы влаги составили в 0-50 см слое почвы 1009 м³/га. Во второй декаде мая шло постепенное снижение влажности почвы на вариантах опыта, так как и в этот период выпадение осадков не наблюдалось. На варианте с орошением был произведен второй полив 20 мая нормой 300 м³/га, что способствовал поднятию влажности почвы до $90 \% \mathrm{HB}$, и соответственно запасы влаги составили 1418 м³/га. На контрольном варианте влажность опустилась до критической отметки - 55 \% НB. В начале третьей декады, 22 мая, выпали осадки нормой $~ 18,3$ мм, что позволило поднять уровень влажности почвы на контроле незначительно, до $59 \%$ НВ.

B первой декаде июня осадков выпало 22,5 мм, и это удерживало запасы влаги на контрольном варианте и орошении соответственно 993-1544 м³/га, или же на уровне 63-98 \% НВ. Вторая декада июня была отмечена выпадением незначительных осадков, что в сумме составило 17 мм. Наблюдалась неболь- шая тенденция к увлажнению почвы, по сравнению с первой декадой, на 4-3 \% НВ. В третьей декаде июня влажность почвы варьировала в пределах 69-94 \% НВ по вариантам опыта.

Июль характеризовался обильными осадками, в течение первой декады выпало три осадка нормами от 12,3 до 15,3 мм с интервалом 3-5 дней. Осадки способствовали благоприятному росту и развитию сельскохозяйственных культур, и в вариантах опыта увеличилась влажность почвы до 78 \% от НВ при контроле, а на опытах с орошением - до 100 \%. Вторая декада также была благоприятной с точки зрения количества осадков для культур опыта. Запасы влаги в варианте без орошения выросли до оптимального уровня в 82 \% НB, в то время как при орошении он варьировался в пределах 100 \% от НВ. В третьей декаде июля, до первого укоса трав, влажность не опускалась ниже порога влажности почвы 80-100\% HB.

Рост и развитие трав второго укоса происходили при достаточном увлажнении почвы во всех изученных вариантах эксперимента, поскольку в первой декаде августа количество осадков составило 23,8 мм. Влажность почвы в вариантах опыта была оптимальной для быстрого роста многолетних трав. В дальнейшие фазы развития трав выпадающие осадки во второй и третьей декаде августа также поддерживали влажность почвы на заданном уровне в 80-100\% HB (рис.).

Сентябрьские осадки, выпавшие в конце первой декады нормой 30 мм, и последующие поддерживали высокий уровень увлажненности почвы.

В таблице 4 представлено суммарное водопотребление, урожайность и коэффициент водопотребления многолетних травосмесей. 







\section{Суммарное водопотребление, урожайность и коэффициент водопотребления многолетних травосмесей}

\begin{tabular}{|c|c|c|c|c|c|c|}
\hline \multirow[b]{2}{*}{ Вариант } & \multicolumn{3}{|c|}{ Приход влаги } & \multirow{2}{*}{$\begin{array}{l}\text { Суммарное водо- } \\
\text { потребление, мм }\end{array}$} & \multirow{2}{*}{$\begin{array}{c}\text { Урожайность, } \\
\text { т/га }\end{array}$} & \multirow{2}{*}{$\begin{array}{c}\text { Коэфффициент } \\
\text { водо- } \\
\text { потребления } \\
\text { мм/т }\end{array}$} \\
\hline & $\begin{array}{c}\text { от } \\
\text { осадков }\end{array}$ & $\begin{array}{c}\text { от } \\
\text { поливов }\end{array}$ & $\begin{array}{c}\text { о запасов } \\
\text { почвы }\end{array}$ & & & \\
\hline $\begin{array}{l}\text { Контроль } \\
\text { (без орошения) }\end{array}$ & $\frac{282}{115}$ & - & $\frac{+36}{+15}$ & 246 & 4,1 & 60 \\
\hline $\begin{array}{l}\text { Орошение } \\
80 \% \text { НВ }\end{array}$ & $\frac{282}{92}$ & $\frac{60}{20}$ & $\frac{+36}{+12}$ & 306 & 9,2 & 33 \\
\hline
\end{tabular}

На изучаемых вариантах опыта расход влаги растениями для роста и развития выглядел следующим образом. Суммарное водопотребление на орошении было выше на 60 мм, чем без орошения. Основу водопотребления на контрольном варианте составили осадки, тогда как на орошаемом варианте на долю осадков приходилось $80 \%$, на долю поливов - $20 \%$. Коэффициенты водопотребления отличались по значениям почти в два раза - на контрольном варианте $60 \mathrm{~mm} / \mathrm{T}$, тогда как на орошении 33 мм/т. К концу вегетации многолетних трав наблюдалось накопление запасов влаги в почве, и оно составило 36 мм по вариантам опыта (см. табл. 4).

\section{Выводы}

1. Влагообеспеченность вегетационного периода в год проведения исследований характеризовалась как недостаточно увлажненная.

2. Наблюдения за динамикой влажности почвы показали, что атмосферные осадки не обеспечивают оптимальную влажность растений, особенно в начале отрастания трав.

3. Для поддержания влажности на уровне 80-100 \% НВ в мае было проведено два полива нормой по 300 м³/га на варианте с орошением.

4. Коэфффициенты водопотребления на орошении почти в два раза выше, чем на богаре.

\section{Литература}

1. Бадмаева С.Э. Эколого-мелиоративные исследования в Средней Сибири. - Красноярск, 2004. - 141 с.

2. Бадмаева С.Э. и др. Инновационные технологии повышения продуктивности агроландшафтов в Восточной Сибири. - Красноярск, 2017. - 375 с.

3. Бадмаева С.Э., Макушкин К.В. Экологическая оценка орошаемых черноземов юга Средней Сибири // Генезис, география, классификация почв и оценка почвенных ресурсов: мат-лы всерос. науч.-практ. конфф. - Архангельск, 2010. - С. 228-231.

4. Безднина С.Я. Экологические основы водопользования. - М.: Изд-во ВНИИ агрохимии, 2005.- $223 \mathrm{c}$.

5. Булгаков В.И., Аванесян И.Л., Капустина T.A. Экологически безопасные нормы орошения, диффреренцированные по ПК зонам Алтайского края // Мелиорация и водное хозяйство. - 2004. - № 4. C. 21-23.

6. Йонко О.А., Коваленко Д.А., Шевченко К.В. Влияние орошения на некоторые свойства черноземов // Черноземы Центральной России: генезис, эволюция и проблемы рационального использования. - Воронеж: Научная книга, 2017. - С. 36-42. 
7. Панфилов В.П. и др. Черноземы: свойства и особенности орошения. - Новосибирск: Наука, 1988. - 256 с.

8. Татаринцев Л.М., Татаринцев В.Л., Пушкарева Т.И. Каштановые почвы Кулундинской степи и их изменение при орошении. Барнаул: Изд-во АГАУ, 2002. - 117 с.

9. Чупрова В.В. Оценка плодородия черноземов Красноярского края // Современное состояние черноземов: мат-лы междунар. науч. конф. - Ростов н/Д., 2013. C. 359-362.

10. Шапорина Н.А., Танасиенко А.А. К вопросу о стратегии и тактике орошения черноземов в Западной Сибири // Сибирский экологический журнал. - 2005. - № 5. С. 801-807.

\section{Literatura}

1. Badmaeva S.E. Ekologo-meliorativnye issledovaniya v Srednej Sibiri. - Krasnoyarsk, 2004. - $141 \mathrm{~s}$.

2. Badmaeva S.E. i dr. Innovacionnye tekhnologii povysheniya produktivnosti agrolandshaftov $\mathrm{v}$ Vostochnoj Sibiri. - Krasnoyarsk, 2017. $375 \mathrm{~s}$.

3. Badmaeva S.E., Makushkin K.V. Ekologicheskaya ocenka oroshaemyh chernozemov yuga Srednej Sibiri // Genezis, geografiya, klassifikaciya pochv i ocenka pochvennyh resursov: mat-ly vseros. nauch.-prakt. konf. Arhangel'sk, 2010. - S. 228-231.
4. Bezdnina S.Ya. Ekologicheskie osnovy vodopol'zovaniya. - M.: Izd-vo VNII agrohimii, 2005. - $223 \mathrm{~s}$.

5. Bulgakov V.I., Avanesyan I.L., Kapustina T.A. Ekologicheski bezopasnye normy orosheniya, differencirovannye po PK zonam Altajskogo kraya // Melioraciya i vodnoe hozyajstvo. 2004. - № 4. - S. 21-23.

6. Jonko O.A., Kovalenko D.A., Shevchenko K.V. Vliyanie orosheniya na nekotorye svojstva chernozemov // CHernozemy Central'noj Rossii: genezis, evolyuciya i problemy racional'nogo ispol'zovaniya. - Voronezh: Nauchnaya kniga, 2017. - S. 36-42.

7. Panfilov V.P. i dr. CHernozemy: svojstva i osobennosti orosheniya. - Novosibirsk: Nauka, 1988. - $256 \mathrm{~s}$.

8. Tatarincev L.M., Tatarincev V.L., Pushkareva T.I. Kashtanovye pochvy Kulundinskoj stepi i in izmenenie pri oroshenii. - Barnaul: Izd-vo AGAU, 2002. - $117 \mathrm{~s}$.

9. Chuprova V.V. Ocenka plodorodiya chernozemov Krasnoyarskogo kraya // Sovremennoe sostoyanie chernozemov: mat-ly mezhdunar. nauch. konf. - Rostov n/D., 2013. - S. 359-362.

10. Shaporina N.A., Tanasienko A.A. K voprosu 0 strategii i taktike orosheniya chernozemov $v$ Zapadnoj Sibiri // Sibirskij ekologicheskij zhurnal. - 2005. - № 5. - S. 801-807. 